\title{
ANALYSIS OF DYNAMIC AND STATIC CHARACTERISTICS OF SUSPENSION BRIDGE WITH WIND CABLES
}

\author{
Long Liu' ${ }^{1}$, Wenqi Li
}

\author{
1. Anyang Institute of Technology, the west end of Huanghe Avenue, Anyang \\ 455000,China;20160913@ayit.edu.cn \\ 2. China Construction Second Bureau Second Construction Engineering Co., Ltd., \\ No.0169, Qianhai Road, Shenzhen,518000,China; 2107596884@qq.com
}

\begin{abstract}
In this paper, a suspension bridge carrying oil pipelines is taken as the research object. A spatial finite element analysis model of the bridge is established for the bridge by using MIDAS/CIVIL finite element analysis software, and the structural analysis of static and dynamic characteristics is carried out. The analysis of dynamic characteristics shows that the wind cable can greatly improve the natural vibration characteristics of the suspension bridge. The analysis of static characteristics shows that the internal forces of the suspender are evenly distributed and the vertical displacement of the main girder of the steel truss is distributed in a parabola, besides, the strength of each main component can meet the safety needs.
\end{abstract}

\section{KEYWORDS}

Pipeline, Suspension bridge, Wind cable, Dynamic, Static

\section{INTRODUCTION}

In addition to being used by people and vehicles, the bridge also has an important function. It can also undertake the crossing obstacles such as oil and gas pipelines. Due to the requirement of crossing rivers and valleys, it is necessary to build some special bridges with large span during the transportation of oil and gas pipelines. Suspension bridges have advantages such as large span capacity, light deadweight, small damping and large flexibility, which make them more competitive in the selection of long-span bridge types. Suspension bridges have strong adaptability to complex terrain and climate. Many suspension span structures have been applied in the transportation process of oil and gas in China. These suspension bridges usually have long spans and are located in complex terrain and climate.

On pipeline, pipe accessories and supporting components, according to the environment, erection forms and working conditions, considering the combination of gravity, variable loading and accidental loading, design and check calculations are carried out. If necessary, wind resistance and seismic dynamic performance analysis should be carried out according to the environment of the pipeline project. As early as 1979, static and dynamic load test research on a $720 \mathrm{~m}$ span suspension bridge was carried out by Deyin Li over the Dnieper River [1]. In 2018, Chong Chen and others made researches on deformation and stress change of long-span suspension bridge under wind load the with the method of finite element analysis [2]. In 2020, Lei Wang and others made analyses of the stress and deformation of suspension bridge under various working conditions [3]. In 2021, Yongzhen Wang and others conducted an experimental study on the structural safety of suspension bridge through scaling test [4].

In this paper, the structure of a suspension bridge with wind cables is analyzed, the spatial finite element model of the suspension bridge is settled by using MIDAS/CIVIL software. The influence of wind cable setting on the dynamic characteristics of the bridge is studied, and the 


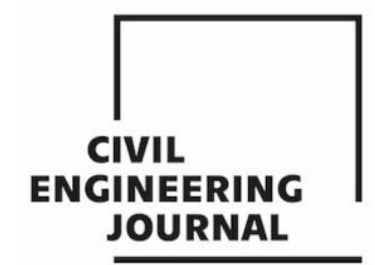

Article no. 43

THE CIVIL ENGINEERING JOURNAL 2-2021

static structure of the whole bridge is analyzed, which can provide a necessary reference for the design and construction of similar bridges.

\section{BACKGROUND}

The span layout of a suspension bridge for a crude oil pipeline is $(29+270+29) \mathrm{m}$, and the elevation of the bridge is shown in Figure1 (a). The vector height of the middle span main cable is $f=22.5 \mathrm{~m}$, the vector to span ratio is $\mathrm{f} / 1=1 / 12$, the suspender spacing is $5 \mathrm{~m}$, and no suspender is set for the side span main cable. The main girder is in the form of steel truss, and every $5 \mathrm{~m}$ is a section. The diameter of crude oil pipeline is $\mathrm{D} 610 \times 12.7 \mathrm{~mm}$. The shape of the main cable is catenary, and the curve cable arrangement is adopted for the wind cable. Its layout is shown in Figure1(b). Parallel wire bundles of $\varphi 7 \mathrm{~mm}$ are used for the main cables and the main cables of the wind cables; parallel wire bundles of $\varphi 5 \mathrm{~mm}$ are used for the hanger rod of the main cables and the stay cable of the wind cables. The tower is made of A-shaped steel tower, and the main limbs and transverse belly bars are made of seamless steel tubes. The tower height $H=29.1 \mathrm{~m}$, the transverse center spacing at the top of the tower $B=1.5 \mathrm{~m}$, and the transverse center spacing at the bottom $B=4.5 \mathrm{~m}$.

(a)

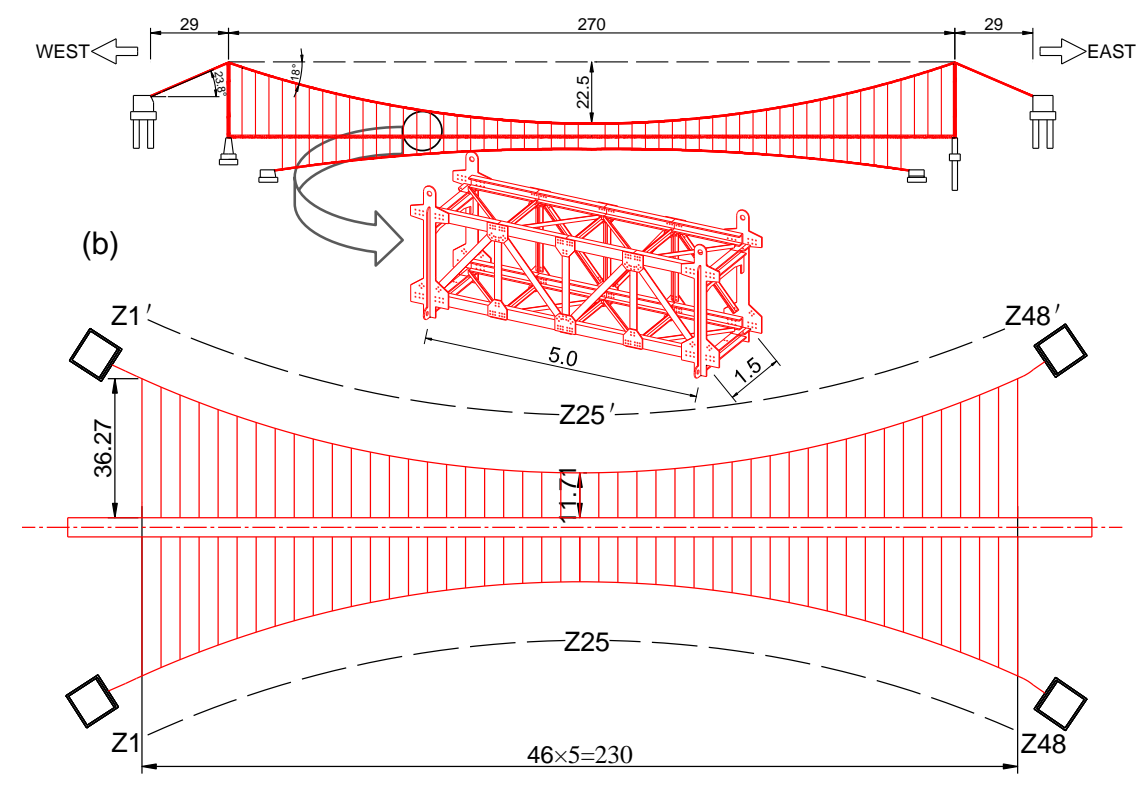

Fig. 1 - Bridge Layout (unit: m) (a) Elevation; (b) Wind cable plan

\section{FINITE ELEMENT MODEL}

MIDAS/CIVIL analysis software is adopted to analyse the suspension bridge with wind cables. Considering the stress characteristics of each component, two types of elements are applied in the finite element analysis of the model: tension-only truss element and beam element.

Tensile only truss units: main cables, main cable derricks, wind cables, and wind cable stays are all used as tension-only truss elements, serving only to transmit the axial tension between the components. This element is a three-dimensional spatial element, and the two nodes of the element have 6 degrees of freedom. There are 408 tension only truss elements in the model.

Beam element: beam element is similar to truss element, since MIDAS/CIVIL carries out spatial three-dimensional calculation, beam element is a spatial element. Each node of the element has 3 translational degrees of freedom and 3 rotational degrees of freedom. Beam element is adopted in the model of steel tower and steel truss beam. There are 2756 beam elements in the model. 


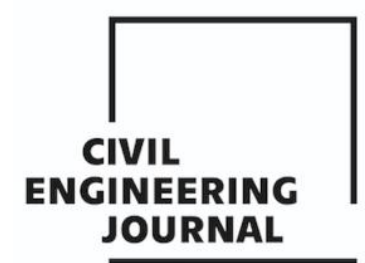

Article no. 43

THE CIVIL ENGINEERING JOURNAL 2-2021

The boundary conditions adopted by the model are as follows: hinge constraints at both ends of the steel truss girder and the bottom of the steel tower (ball hinge structure), fixed constraints at both ends of the main cable and wind cable. For the steel truss girder, which is the hinged connection mode to simulate its joints, the method of releasing beam end hinge constraints is adopted. The gravity of the main cable is taken into account, and the equivalent elastic modulus method proposed by German engineer Ernst in 1932 is adopted to modify the elastic modulus of the main cable.

In order to study the influence of wind cables on the dynamic characteristics of the suspension bridge with wind cables, two different finite element models were established, as shown in Figure 2.

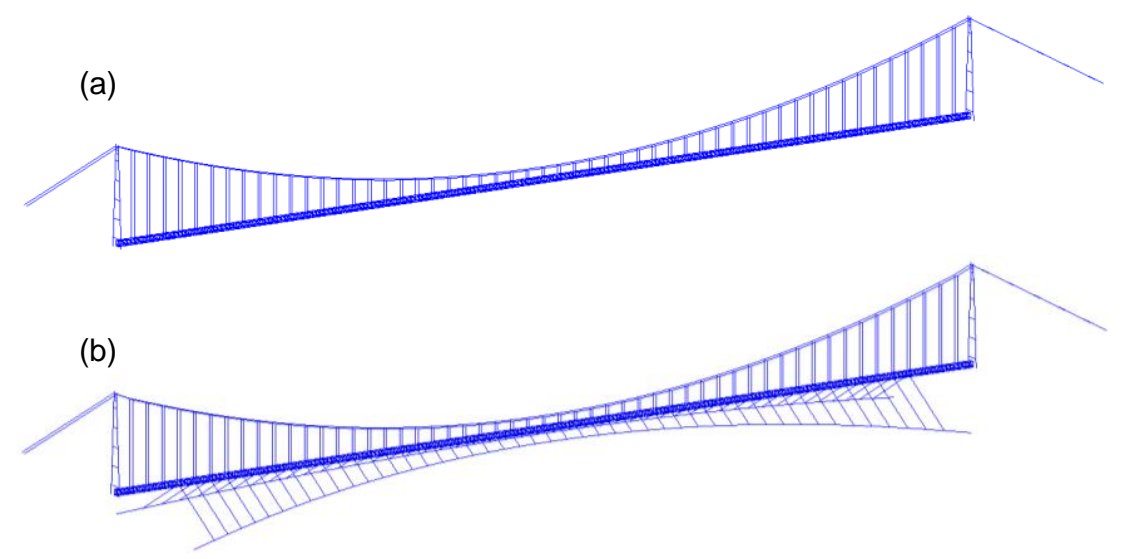

Fig. 2 - Finite element model (a) Without wind cable; (b) With wind cable

\section{DYNAMIC CHARACTERISTICS ANALYSIS}

In this paper, the influence of wind cables on the dynamic characteristics of suspension bridge with wind cables is analyzed.

\section{(1) Dynamic characteristics without wind cables}

First, natural vibration characteristics are analyzed according to the general suspension cable structure without setting wind cable. The Lanczos method is used to calculate the natural vibration characteristics of the bridge, namely, all the loads are converted into mass firstly, and then the structure is discretized through the method of the finite element. The calculated natural frequencies of the first four orders are shown in Table1:

Tab. 1 - Frequency and period of the first fourth order natural vibration (without wind cable)

\begin{tabular}{cccc}
\hline $\begin{array}{c}\text { Mode } \\
\text { number }\end{array}$ & Frequency (cycle/sec) & Period (sec) & Allowable error \\
\hline 1 & 0.067 & 14.912 & 0 \\
2 & 0.184 & 5.435 & 0 \\
3 & 0.184 & 5.426 & 0 \\
4 & 0.317 & 3.150 & 0 \\
\hline
\end{tabular}

Main modes are shown in Figure3: 

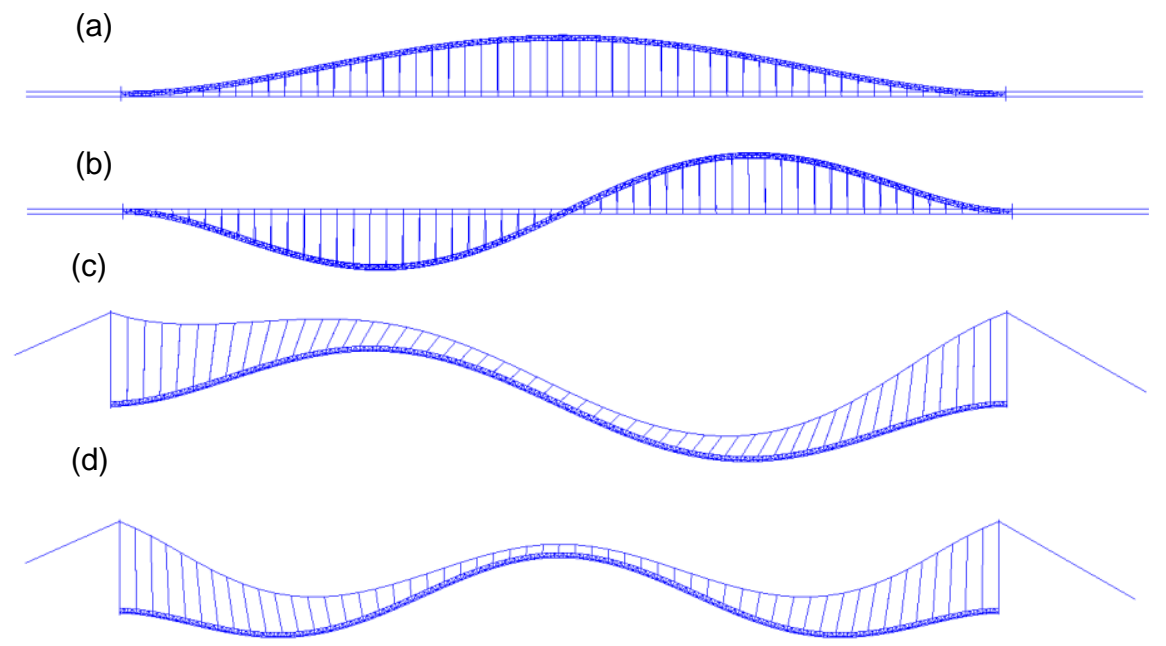

Fig. 3 - Modal diagram of mode shapes without wind cable (a) Mode 1; (b) Mode 2; (c) Mode 3; (d) Mode 4

Table1 lists the first four order natural vibration frequencies and periods of the suspension bridge in the absence of wind cables. The first-order natural vibration period is $14.912 \mathrm{~s}$ and the frequency is $0.067 \mathrm{~Hz}$, indicating that the first-order natural vibration period is relatively long, and the suspension bridge belongs to a long-period without wind cables. Figure 3 shows the first four modes of the suspension bridge in the absence of wind cables, the first-order natural vibration mode characterized by symmetrical transverse bending girder 1 order, second- order natural vibration modal expression is antisymmetric transverse bending girder 1 order, 3 order natural vibration modal of girder antisymmetric order vertical bending, 4 order natural vibration modal of antisymmetric vertical bending girder 2 order. It can be seen that without wind cables, the structural natural vibration is first manifested as transverse bending, indicating that the suspension bridge is more affected by transverse wind load or transverse seismic force, while the vertical bending appears later [5-7].

\section{(2) Dynamic properties with wind cables}

Since the main girder with small size and greater flexibility is usually used in the suspension bridge, wind cables can be installed in this type of bridges. As shown in Figure 1 and Figure 2 (b), wind cables are also installed in the suspension bridge. The main cable of the wind cable is curved in space, and the plane where the wind cable stays is at an angle of 30 degrees from the horizontal plane. The natural vibration characteristics of the suspension bridge are calculated when wind cables are set, and the obtained first four natural vibration frequencies and periods are shown in Table 2:

Tab. 2 - Frequency and period of the first fourth order natural vibration (with wind cable)

\begin{tabular}{cccc}
$\begin{array}{c}\text { Mode } \\
\text { number }\end{array}$ & Frequency (cycle/sec) & Period (sec) & Allowable error \\
\hline 1 & 0.338 & 2.955 & $0.00 \mathrm{E}+00$ \\
2 & 0.431 & 2.322 & $0.00 \mathrm{E}+00$ \\
3 & 0.745 & 1.342 & $5.23 \mathrm{E}-83$ \\
4 & 0.795 & 1.258 & $5.28 \mathrm{E}-76$ \\
\hline
\end{tabular}

Main modes are shown in Figure 4: 

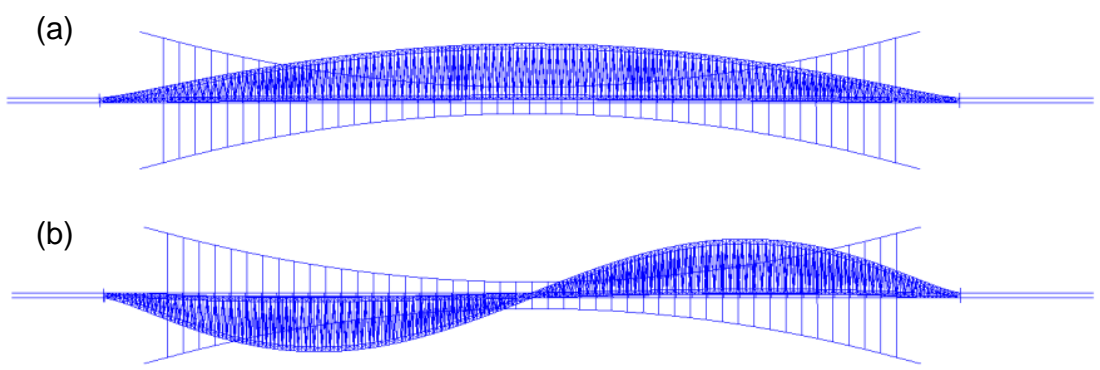

(c)

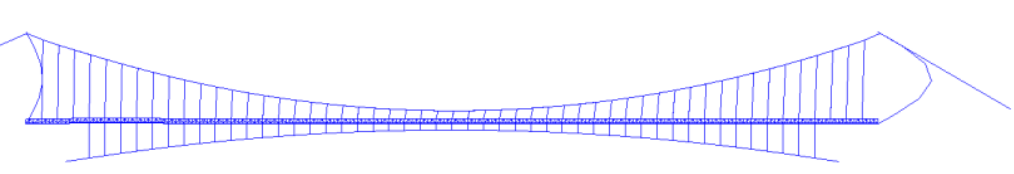

(d)

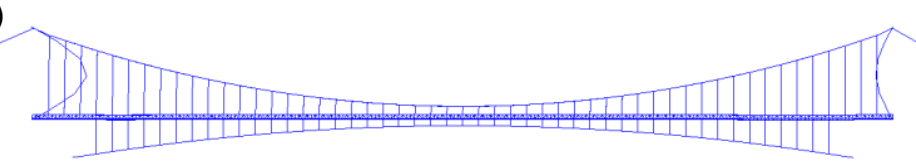

Fig. 4 - Modal diagram of mode shapes with wind cable (a) Mode 1; (b) Mode 2; (c) Mode 3; (d) Mode 4

After considering the influence of wind cables, the first four order natural vibration frequencies and periods are given in Table 2. The first-order natural vibration period is $2.955 \mathrm{~s}$, and the frequency is $0.338 \mathrm{~Hz}$. Compared with the condition in the absence of wind cables, the natural vibration period is reduced greatly, while the natural vibration frequency is increased greatly. Figure4 shows the first four modes of the suspension bridge with wind cables installed, and their modal characteristics are different from those in the case of no wind cables. The main girder of the first-order natural mode still shows symmetrical transverse bending, but its vibration amplitude is limited by the wind cables, and the amplitude is obviously reduced. Similarly, the second-order natural vibration mode also shows similar characteristics, and the third and fourth- order vibration modes are mainly tower deformation. It can be seen that the installation of wind cables plays an obvious role in suppressing the vibration of the main girder, especially in the transverse direction, the vibration of the main girder is greatly suppressed. It can be predicted that if the angle between the plane where the wind cable is located and the horizontal plane is further reduced, the wind cable will play a greater role in improving the natural vibration characteristics of the main girder.

\section{STATIC CHARACTERISTICS ANALYSIS}

\section{(1) Force analysis of main cable}

The suspension bridge has two main cables side by side, with a transverse spacing of $1.5 \mathrm{~m}$. After the bridge is completed and in operation, the main cable will act as the core bearing component under acting gravity and the live load of oil transmission. Under various load conditions, the internal forces of each unit of the main cables are shown in Figure 5: 


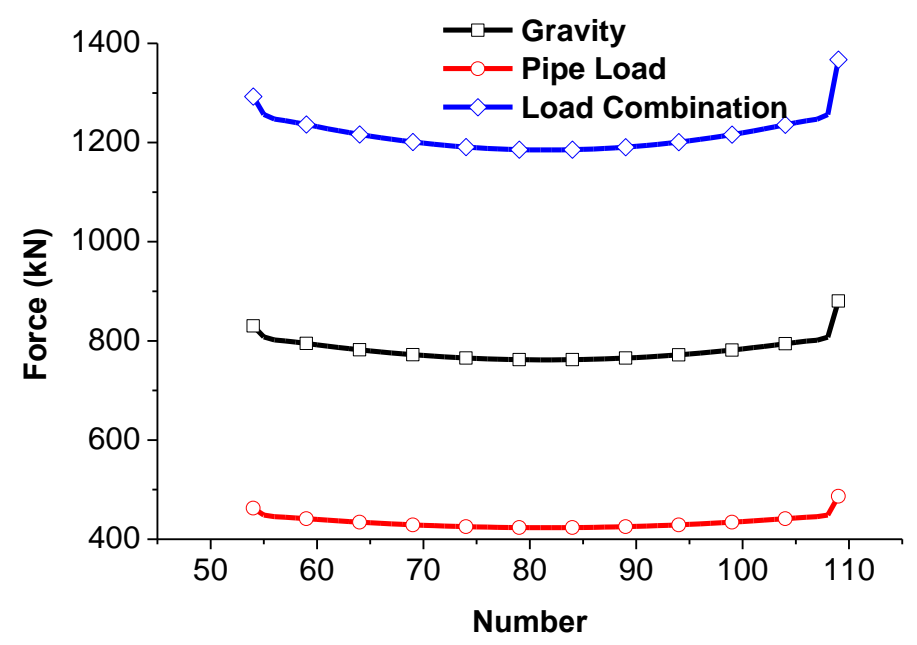

Fig. 5 - Force of main cable

According to Figure 5, during the operation of the bridge, the force of the main cables gradually decreases from the fulcrum to the middle of the span, and the force of Unit 54 and Unit 109 near the fulcrum receive greater internal forces. Under the acting load combination, the internal forces of No. 54 side main cable and No. 109 side main cable are respectively $1293 \mathrm{kN}$ and $1367 \mathrm{kN}$, and the different internal forces of the two elements are caused by the different horizontal angles. Among them, the horizontal Angle of Unit 54 is 23.8 degrees, and that of Unit 109 is 29.6 degrees, that is, the greater the degree of inclination, the greater the force. The maximum stress of the main cable is $294 \mathrm{MPa}$, less than the allowable stress $\sigma=1670 / 3=557 \mathrm{MPa}$, which can meet the strength requirements.

\section{(2) Force analysis of main cable derrick}

The suspension bridge has a total of 53 pairs of hanger rods, and the spacing between the hanger rods is $5 \mathrm{~m}$. After the completion of the bridge, the tension of the derrick under various load conditions is shown in Figure 6:

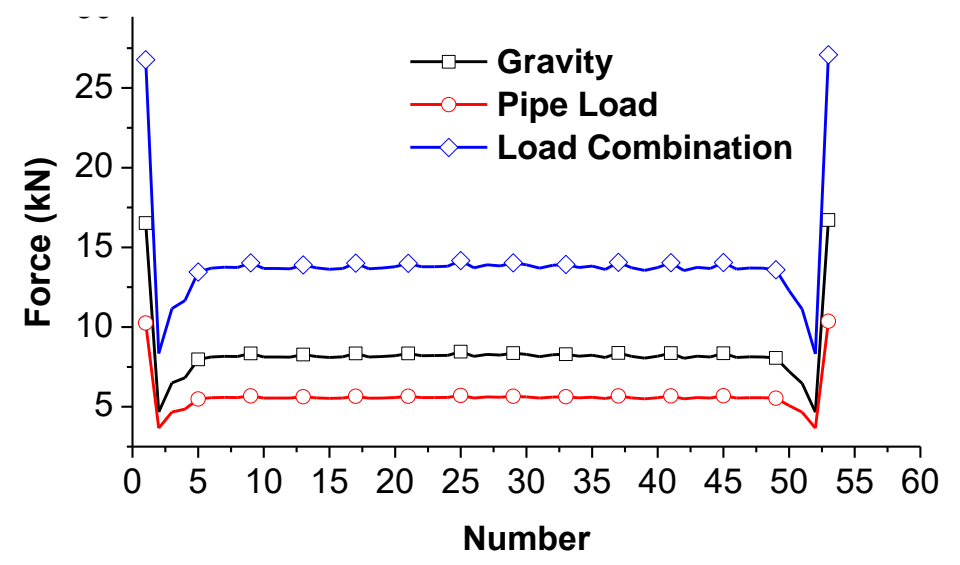

Fig. 6 - Force of derrick

As can be seen from Figure 6, except for the internal forces of No. 1, No. 2, No. 52, and No. 53 derricks on both sides, the internal forces of No. 3 to 51 derricks are relatively uniform. Under the action of load combination, the maximum internal force of the derrick is $27.08 \mathrm{kN}$, and the stress of the derrick is $105 \mathrm{MPa}$, which can meet the strength requirements. In the load combination, the contribution of the structure's dead weight to the internal force of the derrick is $60 \%$, while the crude oil load during operation is only $40 \%$. 


\section{(3) Displacement analysis of main girder}

The displacing the main beam of the steel truss under the action of gravity, crude oil load and load combination is solved, and the vertical displacement of the lower edge node of the main beam of the steel truss is extracted, as shown in Figure 7:

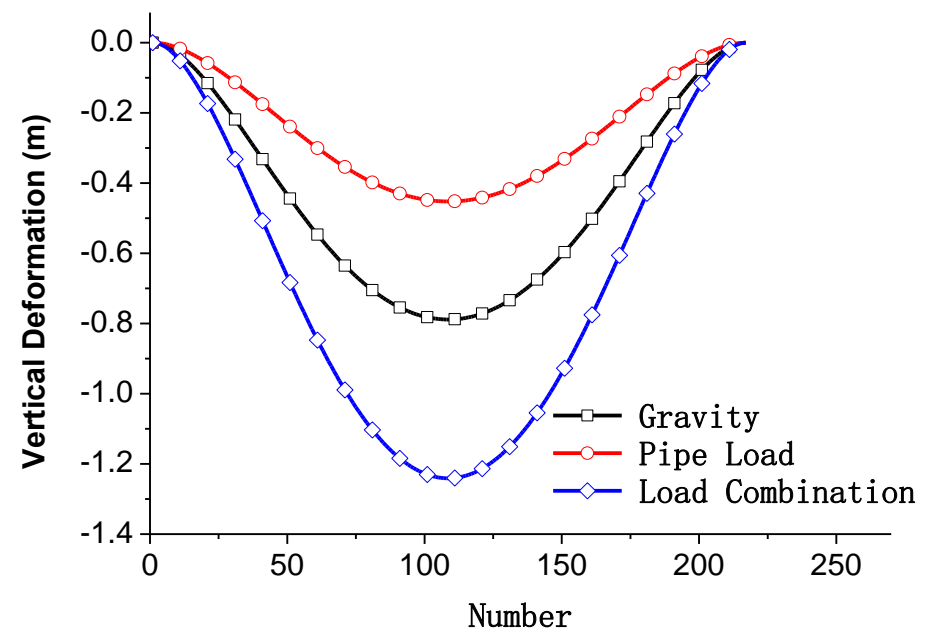

Fig. 7 - Vertical displacement of main girder

It can be seen from Figure 7 the vertical displacement of the main girder under the action of gravity and crude oil is in the form of a parabola. The maximum vertical displacement of the main girder in the middle span under the action of gravity is $0.79 \mathrm{~m}$, the maximum vertical displacement under the action of crude oil is $0.45 \mathrm{~m}$, and the maximum vertical displacement of the main girder is $1.24 \mathrm{~m}$ under the load combination. The allowable displacement value of the suspension bridge is $L / 150=1.8 \mathrm{~m}$, and the deformation value of the suspension bridge can meet the requirements.

\section{(4) Strength check of component}

The suspension bridge adopts the form of steel structure, which has the advantages of light weight, fast construction and convenient standardization construction. The strength of the main components of the bridge is checked, and the maximum stress of each component is shown in Table 3:

Tab. - 3 Strength check of main components

\begin{tabular}{cccc}
\hline Component & Stress(MPa) & Allowable strength(MPa) & Check result \\
\hline Main cable & 294 & 557 & Satisfy \\
Main cable derrick & 105 & 557 & Satisfy \\
Wind cable & 212 & 557 & Satisfy \\
Pipe & 20 & 120 & Satisfy \\
Main girder & 149 & 175 & Satisfy \\
Tower & -28 & 175 & Satisfy \\
\hline
\end{tabular}

Note: positive stress means tensile stress, negative stress means compressive stress.

As can be seen from Table 3, the stress value of the main cable of the suspension bridge is the largest, which is $294 \mathrm{MPa}$. The maximum stress generated by other major components can meet strength requirements, which can ensure its safe use [8-10]. 


\section{CONCLUSION}

In this paper, a suspension bridge with wind cables is analyzed, mainly including dynamic and static characteristics analysis, and the conclusions are as follows:

(1) Without wind cables, the first-order natural vibration period of the suspension bridge is $14.912 \mathrm{~s}$, and the frequency is $0.067 \mathrm{~Hz}$. The natural vibration mode is first displayed as transverse vibration, indicating that it is more affected by transverse wind load; with wind cables, the first-order natural vibration period of the suspension bridge is $2.955 \mathrm{~s}$, and the frequency is $0.338 \mathrm{~Hz}$, and the transverse vibration is greatly improved.

(2) Under the influence each load, the force of the main cable element gradually decreases from the two fulcrum points to the middle of the span, and the force received by the main cable elements on both sides is the largest, and the internal force is related to the degree of horizontal tilt. For the derricks, except the units near the fulcrum, the internal force distribution of the remaining derricks is relatively uniform.

(3) Under acting each load, the vertical displacement of the main girder of the steel truss presents a parabolic distribution. Under acting load combination, the maximum mid-span displacement value is $1.24 \mathrm{~m}$, which meets the requirements of deformation permission.

(4) After checking the strength of the main components, the stress can meet the requirements of the allowed strength, which can ensure the safe of the structure.

\section{ACKNOWLEDGEMENTS}

This paper is supported by the Anyang Science and Technology Plan Project (2020) (grant number: 251) and Anyang Institute of Technology Research and Cultivation Fund (grant number: YPY2020021).

\section{REFERENCES}

[1] LI Deyin, 1996. Real Bridge Test of $720 \mathrm{~m}$ Suspension Pipeline Bridge over Dnieper River. Foreign Bridges. vol.01:7-9.

[2] Chen Chong, Hou Yue, Jiao Quan, Su Junwei, Zhang Shimin, 2018. Stress Analysis of Large Span Oil and Gas Pipeline of Suspension Bridge under Wind Load. Pipeline Technology and Equipment, vol.01:45-50.

[3] Wang Lei, Yue Sanqi, Zhao Zhichao, 2020. Calculation and analysis of bearing capacity of suspension bridge of long distance natural gas transmission pipeline. Engineering Construction, vol.52(03):23-27.

[4] Wang Yongzhen, Huo Sitong, Zeng Weiguo, Lin Nan, Ju Meng, 2021. Structural Safety Analysis of Suspension Bridge Based on Scaling Model. Oil-Gas Field Surface Engineering, vol.40(01):13-17+24.

[5] Wang Lifeng, Sun Yong, Wang Ziqiang, 2010. Comparative analysis of dynamic characteristics of self-anchored suspension bridge and ground anchored suspension bridge. Chinese and foreign highways, vol. 4:156-159.

[6] Zhang Jie. Structural Safety Analysis of Large Span Suspension Pipeline. Chongqing: Chongqing University, 2008.

[7] Huang Lihua, Li Bing, Lei Gang, Shi Dongdong, 2010. Analysis of Dynamic Characteristics of Long Span Suspension Pipeline Bridge. Industrial Building, vol.S1:271-273+348.

[8] Yin Shutao. Study on Wind-induced Response of Long-span Pipe Suspension Bridge. Dalian, Dalian University of Technology, 2010.

[9] LI Bing. Static, Dynamic and Buffeting Analysis of Suspension Pipe Bridge. Dalian, Dalian University of Technology, 2010.

[10] Ni Yuewu, Zhang Xinyu, Tian Yu, 2010. Test and Evaluation Analysis of a Pipeline Bridge. World Bridge, vol. 03:74-77. 